\title{
New ultrahigh-resolution picture of Earth's gravity field
}

\author{
Christian Hirt, ${ }^{1}$ Sten Claessens, ${ }^{1}$ Thomas Fecher, ${ }^{2}$ Michael Kuhn, ${ }^{1}$ Roland Pail, ${ }^{2}$ \\ and Moritz Rexer ${ }^{1,2}$
}

Received 11 July 2013; revised 2 August 2013; accepted 6 August 2013; published 28 August 2013.

[1] We provide an unprecedented ultrahigh resolution picture of Earth's gravity over all continents and numerous islands within $\pm 60^{\circ}$ latitude. This is achieved through augmentation of new satellite and terrestrial gravity with topography data and use of massive parallel computation techniques, delivering local detail at $\sim 200 \mathrm{~m}$ spatial resolution. As such, our work is the first-of-its-kind to model gravity at unprecedented fine scales yet with nearglobal coverage. The new picture of Earth's gravity encompasses a suite of gridded estimates of gravity accelerations, radial and horizontal field components, and quasi-geoid heights at over 3 billion points covering $80 \%$ of Earth's land masses. We identify new candidate locations of extreme gravity signals, suggesting that the Committee on Data for Science and Technology standard for peak-to-peak variations in free-fall gravity is too low by about $40 \%$. The new models are beneficial for a wide range of scientific and engineering applications and freely available to the public. Citation: Hirt, C., S. Claessens, T. Fecher, M. Kuhn, R. Pail, and M. Rexer (2013), New ultrahighresolution picture of Earth's gravity field, Geophys. Res. Lett., 40, 4279-4283, doi:10.1002/grl.50838.

\section{Introduction}

[2] Precise knowledge of the Earth's gravity field structure with high resolution is essential for a range of disciplines, as diverse as exploration and potential field geophysics [Jacoby and Smilde, 2009], climate and sea level change research [Rummel, 2012], surveying and engineering [Featherstone, 2008], and inertial navigation [Grejner-Brzezinska and Wang, 1998]. While there is a strong scientific interest to model Earth's gravity field with ever-increasing detail, the resolution of today's gravity models remains limited to spatial scales of mostly 2-10 km globally [Pavlis et al., 2012; Balmino et al., 2012], which is insufficient for local gravity field applications such as modeling of water flow for hydroengineering, inertial navigation, or in situ reduction of geophysical gravity field surveys. Up until now, gravity models with sub-kilometer resolution are unavailable for large parts of our planet.

[3] Here we provide an unprecedented ultrahigh resolution view of five components of Earth's gravity field over all

Additional supporting information may be found in the online version of this article.

${ }^{1}$ Western Australian Centre for Geodesy, Curtin University, Perth, Western Australia, Australia.

${ }^{2}$ Institute for Astronomical and Physical Geodesy, Technical University of Munich, Munich, Germany.

Corresponding author: C. Hirt, Western Australian Centre for Geodesy, Curtin University, GPO Box 1987, Perth, WA 6845, Australia. (c.hirt@curtin.edu.au)

(C)2013. American Geophysical Union. All Rights Reserved. 0094-8276/13/10.1002/grl.50838 continents, coastal zones, and numerous islands within $\pm 60^{\circ}$ latitude. This is achieved through augmentation of new satellite and terrestrial gravity with topography data [e.g., Hirt et al., 2010] and use of massive parallel computation techniques, delivering local detail at $7.2 \operatorname{arc} \sec (\sim 200 \mathrm{~m}$ in north-south direction) spatial resolution (section 2). As such, our work is the first-of-its-kind to model gravity at ultrafine scales yet with near-global coverage. The new picture of Earth's gravity encompasses a suite of gridded estimates of gravity accelerations, radial and horizontal field components, and quasi-geoid heights at over 3 billion points covering $80 \%$ of Earth's land masses and $99.7 \%$ of populated areas (sections 3 and 4). This considerably extends our current knowledge of the gravity field. The gridded estimates are beneficial for a range of scientific and engineering applications (section 5) and freely available to the public. Supporting information is available providing full details on the methods applied in this study.

\section{Data and Methods}

[4] Our ultrahigh resolution picture of Earth's gravity field is a combined solution based on the three key constituents GOCE/GRACE satellite gravity (providing the spatial scales of $\sim 10,000$ down to $\sim 100 \mathrm{~km})$, EGM2008 $(\sim 100$ to $\sim 10 \mathrm{~km})$, and topographic gravity, i.e., the gravitational effect implied by a high-pass filtered terrain model (scales of $\sim 10 \mathrm{~km}$ to $\sim 250 \mathrm{~m}$ ).

[5] Regarding the satellite component, we use the latest satellite-measured gravity data (release GOCE-TIM4) from the European Space Agency's GOCE satellite [Drinkwater et al., 2003; Pail et al., 2011], parameterized as coefficients of a spherical harmonic series expansion, that currently provides the highest-resolution picture of Earth's gravity ever obtained from a space gravity sensor. Resolving gravity field features at spatial scales as short as 80-100 km, GOCE confers new gravity field knowledge, most notably over poorly surveyed regions of Africa, South America, and Asia [Pail et al., 2011].

[6] Compared to pure GOCE models, complementary GRACE satellite gravity [Mayer-Gürr et al., 2010] is superior in the spectral range up to degrees 70-80 [Pail et al., 2010]. Therefore, first, a combined satellite-only solution based on full normal equations of GRACE (up to degree 180) and GOCE (up to degree 250) is computed [see, e.g., Pail et al., 2010]. The GRACE/GOCE combination is then merged with EGM2008 [Pavlis et al., 2012] using the EGM2008 coefficients as pseudo-observations. Since for EGM2008 only the error variances are available, the corresponding normal equations have diagonal structure. In our combination, GRACE/GOCE data have dominant influence in the spectral band of harmonic degrees 0 to 180 with EGM2008 information taking over in the spectral range 


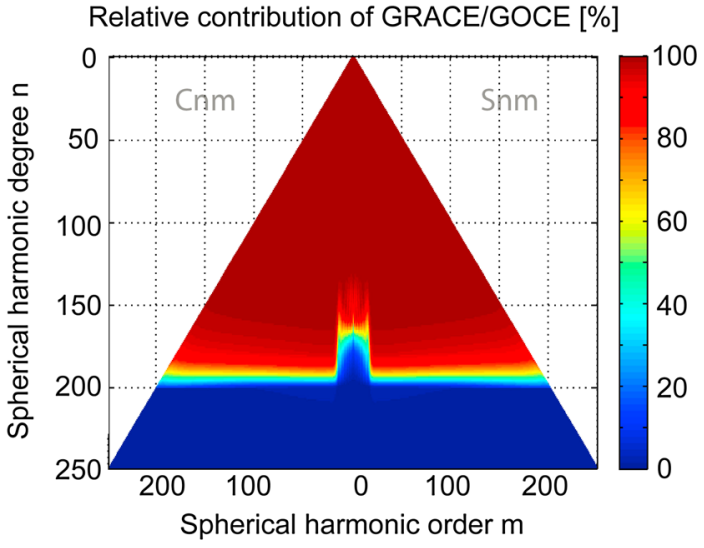

Figure 1. Relative contribution of GOCE/GRACE data per spherical harmonic coefficient in the combination with EGM2008 data (in percent) for the degrees 0 to 250 .

200 to 2190 , leaving the main spectral range of transition from GRACE/GOCE to EGM2008 in spectral band of degrees 181 to 200. The relative contributions of EGM2008 and GRACE/GOCE satellite gravity are shown in Figure 1.

[7] The spherical harmonic coefficients of the combined GRACE/GOCE/EGM2008 (GGE) gravity model were used in the spectral band of degrees 2 to 2190 to synthesize a range of frequently used gravity field functionals at the Earth's surface. For accurate spherical harmonic synthesis at the Earth's surface, as represented through the Shuttle Radar Topography Mission (SRTM) topography, the gradient approach to fifth order [Hirt, 2012] was applied. This numerically efficient evaluation technique takes into account the effect of gravity attenuation with height. Applying the gradient approach as described in Hirt [2012] yielded numerical estimates for radial derivatives (gravity disturbances) and horizontal derivatives (deflections of the vertical) of the disturbing potential and quasi-geoid heights from the GGE data set at 7.2 arc sec resolution (about 3 billion surface points) within the SRTM data coverage.

[8] For the Mount Everest region, Figure 2 exemplifies the associated resolution of GOCE/GRACE satellite gravity (a) and their combination with EGM2008 gravity (b). The spatial resolution of the GGE gravity field functionals is limited to about $\sim 10 \mathrm{~km}$ (or harmonic degree of 2190) which leaves the problem of modeling the field structures at short scales, down to few $100 \mathrm{~m}$ resolution at any of the surface points.

[9] Because ground gravity measurements at a spatial density commensurate with our model resolution do not exist over most parts of Earth [e.g., Sansò and Sideris, 2013] — and will not become available in the foreseeable future - alternative solutions are required to estimate the gravity field signals at scales shorter than $10 \mathrm{~km}$. High-resolution topography data is widely considered the key to ultrahigh-resolution gravity modeling and used successfully as effective means to estimate short-scale gravity effects [Sansò and Sideris, 2013; Tziavos and Sideris, 2013; Pavlis et al., 2012; Forsberg and Tscherning, 1981]. This is because the short-scale gravity field is dominated by the constituents generated by the visible topographic masses [Forsberg and Tscherning, 1981]. However, forward estimation of the short-scale gravity field constituents from elevation models near-globally at ultrahigh (few 100 meters) resolution is computationally demanding. Yet we have accomplished this challenge for the first time through advanced computational resources.

[10] Massive parallelization and the use of Western Australia's iVEC/Epic supercomputing facility allowed us to convert topography from the Shuttle Radar Topography Mission (SRTM) [cf. Jarvis et al., 2008] — along with bathymetric information along coastlines [Becker et al., 2009] - to topographic gravity at 7.2 arc sec resolution everywhere on Earth between $\pm 60^{\circ}$ latitude with SRTM data available. Based on nonparallelized standard computation techniques, the calculation of topographic gravity effects would have taken an estimated 20 years, which is why previous efforts were restricted to regional areas [Kuhn et al., 2009; Hirt, 2012].

[11] The conversion of topography to topographic gravity is based on the residual terrain modeling technique [Forsberg, 1984], with the topography high-pass filtered through subtraction of a spherical harmonic reference surface (of degree and order 2160) prior to the forward modeling. We treated the ocean water masses and those of the major inland water bodies (Great Lakes, Baikal, Caspian Sea) using a combination of residual terrain modeling with the concept of rock-equivalent topography [Hirt, 2013], whereby the water masses were "compressed" to layers equivalent to topographic rock. These procedures yield short-scale topographic gravity that is suitable for augmentation of degree 2190 spherical harmonic gravity models beyond their associated $10 \mathrm{~km}$ resolution [cf. Hirt, $2010,2013]$. The topographic gravity is based on a mass-
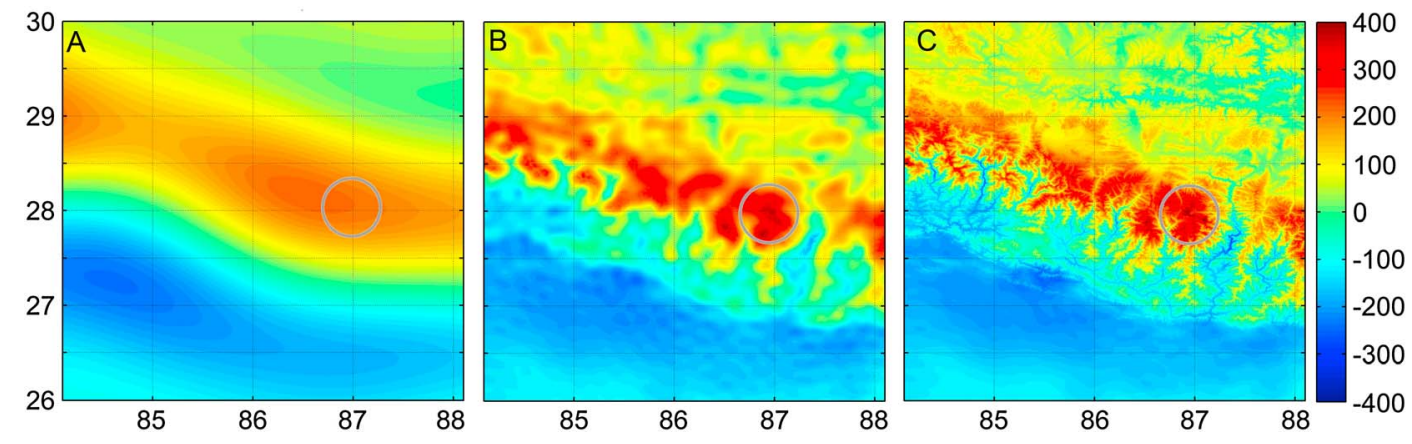

Figure 2. Gravity field at different levels of resolution over Mount Everest area. (a) Satellite-only (free-air) gravity from GOCE and GRACE satellites, (b) GGE gravity (satellite gravity combined with EGM2008 gravity), and (c) GGMplus as composite of satellite gravity, EGM2008, and topographic gravity. Shown is the radial component of the gravity field over a $\sim 400 \times 400 \mathrm{~km}$ area covering parts of the Southern Himalayas including the Mount Everest summit area (marked), units in $10^{-5} \mathrm{~m} \mathrm{~s}^{-2}$. The spatial resolution of the gravity modeling increases from $\sim 100 \mathrm{~km}, \sim 10 \mathrm{~km}$ to ultra-fine $\sim 200 \mathrm{~m}$ spatial scales. 
Table 1. Descriptive Statistics of the GGMplus Model Components Calculated at 3,062,677,383 Land and Near-Coastal Points Within $\pm 60^{\circ}$ Geographic Latitude ${ }^{\mathrm{a}}$

\begin{tabular}{|c|c|c|c|c|c|}
\hline Gravity Model Component & & Min & Max & RMS & Unit \\
\hline \multirow[t]{2}{*}{ Gravity } & Free-fall acceleration & 976392 & 981974 & 980133 & $10^{-5} \mathrm{~m} \mathrm{~s}^{-2}$ \\
\hline & Radial component & -456 & 714 & 48.0 & $10^{-5} \mathrm{~m} \mathrm{~s}^{-2}$ \\
\hline \multirow[t]{3}{*}{ Horizontal components } & North-south & -108 & 94 & 6.9 & $\operatorname{arc~sec}$ \\
\hline & East-west & -83 & 79 & 6.8 & $\operatorname{arcsec}$ \\
\hline & Total (magnitude) & 0 & 109 & 9.4 & $\operatorname{arc~sec}$ \\
\hline Quasi-geoid & & -99.26 & 86.60 & 29.91 & $\mathrm{~m}$ \\
\hline
\end{tabular}

${ }^{\mathrm{a}} \mathrm{RMS}$ is the root-mean-square of the component.

density assumption of $2670 \mathrm{~kg} \mathrm{~m}^{-3}$ and provides the spatial scales of $\sim 10$ to $\sim 250 \mathrm{~m}$, which is complementary to the GGE gravity (spatial scales from $\sim 10,000 \mathrm{~km}$ to $\sim 10 \mathrm{~km}$ ).

\section{Results}

[12] Addition of both components (GGE and topographic gravity) results in the ultrahigh-resolution model GGMplus (Global Gravity Model, with plus indicating the leap in resolution over previous $10 \mathrm{~km}$ resolution global gravity models). The modeled gravity field components and their descriptive statistics are reported in Table 1.

[13] This world's first ultrahigh resolution modeling over most of Earth's land areas delivered us the expected gravity signatures of small-scale topographic features-such as mountain peaks and valleys — which are otherwise masked in $10 \mathrm{~km}$ resolution models. This adds much local detail to the gravity maps (compare Figures $2 \mathrm{~b}$ and $2 \mathrm{c}$ ) and yields a spectrally more complete and accurate description of the gravity field [e.g., Hirt, 2012].

[14] Our gridded estimates portray the subtle variations of gravity (Figure 3) which are known to depend on factors such as location, height, and presence of mass-density anomalies. GGMplus reveals a candidate location for the minimum gravity acceleration on Earth: the Nevado Huascarán summit (Peru) with an estimated acceleration of $9.76392 \mathrm{~m} \mathrm{~s}^{-2}$ (Figures $3 \mathrm{a}$ and $3 \mathrm{~b}$ and Table 2). A candidate location for Earth's maximum gravity acceleration was identified—outside the SRTM area, based on GGE only - in the Arctic Sea with an estimated $9.83366 \mathrm{~m} \mathrm{~s}^{-2}$. This suggests a variation range
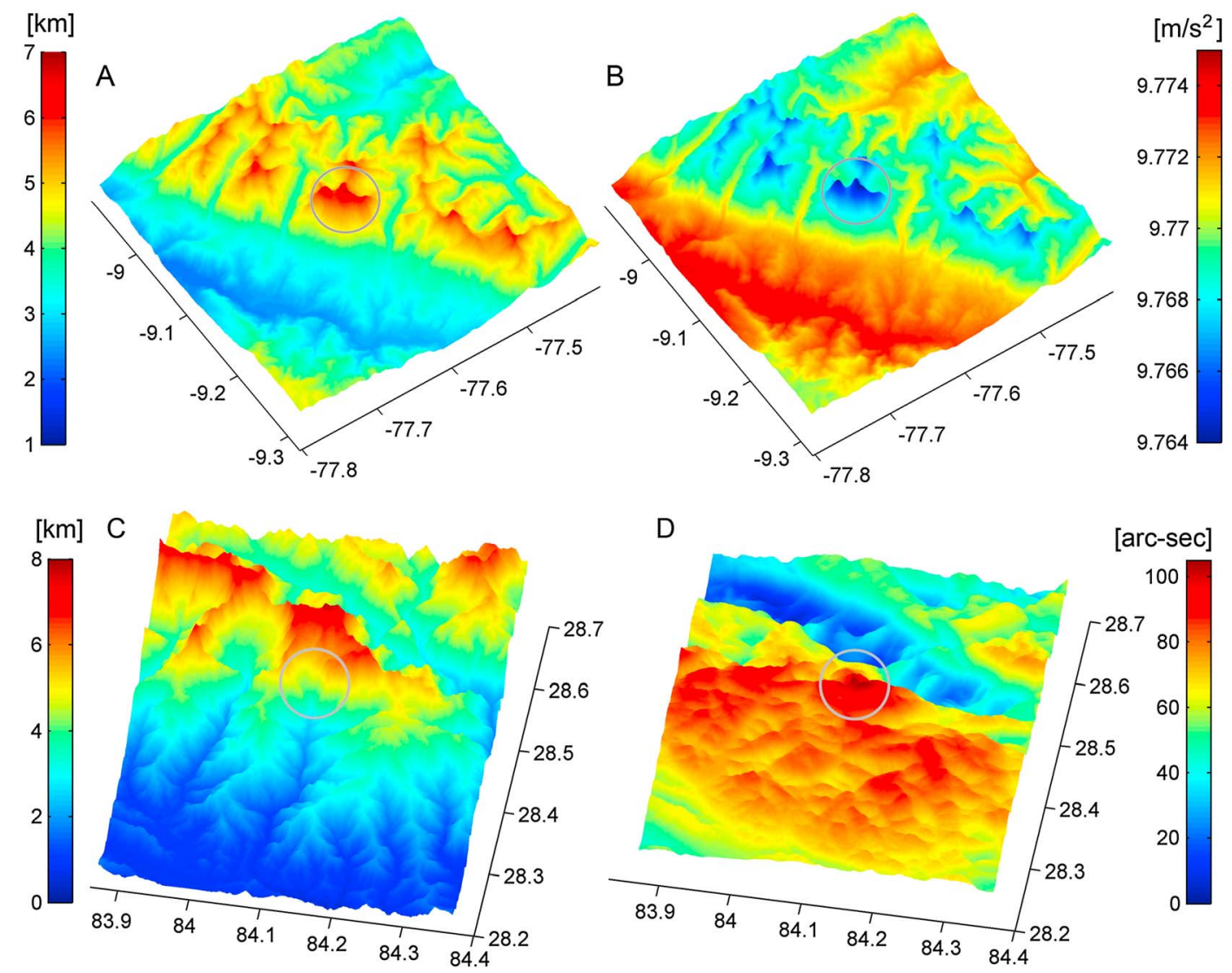

Figure 3. Candidate locations of some extreme signals in Earth's gravity in the Andes and Himalaya regions. (a) Topography and (b) free-fall gravity accelerations over the Huascarán region (Peru), where GGMplus gravity accelerations are as small as $\sim 9.764 \mathrm{~m} \mathrm{~s}^{-2}$. (c) Topography and (d) GGMplus total horizontal field component over the Annapurna II region (Nepal). The gravitational attraction of the Annapurna II masses is expected to cause an extreme slope of the quasi/geoid with respect to the Earth ellipsoid of up to $\sim 109$ arc sec. 
Table 2. Candidate Locations for Extreme Values of Earth's Gravity Field

\begin{tabular}{|c|c|c|c|}
\hline Gravity Component & Minimum/Maximum & Latitude/Longitude & Geographic Feature/Location \\
\hline Gravity acceleration & $\begin{array}{l}9.76392 \mathrm{~m} \mathrm{~s}^{-2} \\
9.83366 \mathrm{~m} \mathrm{~s}^{-2}\end{array}$ & $\begin{array}{c}-9.12^{\circ} /-77.60^{\circ} \\
86.71^{\circ} / 61.29^{\circ}\end{array}$ & $\begin{array}{c}\text { Huascarán, Peru } \\
\text { Arctic Sea }\end{array}$ \\
\hline Radial component & $\begin{array}{l}-456 \times 10^{-5} \mathrm{~m} \mathrm{~s}^{-2} \\
714 \times 10^{-5} \mathrm{~m} \mathrm{~s}^{-2}\end{array}$ & $\begin{array}{c}29.71^{\circ} / 95.36^{\circ} \\
10.83^{\circ} /-73.69^{\circ}\end{array}$ & $\begin{array}{l}\text { Gandengxiang, China } \\
\text { Pico Cristóbal Colón, Columbia }\end{array}$ \\
\hline Horizontal component $\mathrm{t}^{\mathrm{b}}$ & 109 arc sec & $28.45^{\circ} / 84.13^{\circ}$ & $\sim 10 \mathrm{~km}$ south of Annapurna II, Nepal \\
\hline Quasi-geoid & $\begin{array}{c}-106.59 \mathrm{~m} \\
86.60 \mathrm{~m}\end{array}$ & $\begin{array}{l}4.71^{\circ} / 78.79^{\circ} \\
-8.40^{\circ} / 147.35^{\circ}\end{array}$ & $\begin{array}{l}\text { Laccadive Sea, south of Sri Lanka } \\
\text { Puncak Trikora, Papua, Indonesia }\end{array}$ \\
\hline
\end{tabular}

${ }^{a}$ Offshore area, value estimated without topographic gravity using GGE-only (10 km resolution, also see supporting information).

${ }^{\mathrm{b}}$ Total component computed as magnitude from the north-south and east-west components.

(peak-to-peak variation) for gravity accelerations on Earth of about $\sim 0.07 \mathrm{~m} \mathrm{~s}^{-2}$, or $0.7 \%$, which is about $40 \%$ larger than the variation range of $0.5 \%$ implied by standard models based on a rotating mass-ellipsoid (gravity accelerations are $9.7803 \mathrm{~m} \mathrm{~s}^{-2}$ (equator) and $9.8322 \mathrm{~m} \mathrm{~s}^{-2}$ (poles) on the mass-ellipsoid [cf. Moritz, 2000]). So far, such a simplified model is also used by the Committee on Data for Science and Technology to estimate the variation range in free-fall acceleration on Earth [Mohr and Taylor, 2005]. However, due to the inhomogeneous structure of Earth, presence of topographic masses and decay of gravity with height the actual variations in free-fall accelerations are $\sim 40 \%$ larger at the Earth's surface (Table 2).

[15] GGMplus free-air gravity - the radial component of Earth's gravity field - varies within a range of $\sim 0.011 \mathrm{~m}$ $\mathrm{s}^{-2}(\sim 0.1 \%$ of gravity accelerations) with its minimum value of $-456 \times 10^{-5} \mathrm{~m} \mathrm{~s}^{-2}$ located in China and its maximum of $714 \times 10^{-5} \mathrm{~m} \mathrm{~s}^{-2}$ located over the Pico Cristóbal Colón summit in Colombia. The higher variability of gravity accelerations over free-air gravity reflects the well-known fact that gravity accelerations include the gravitational attraction and centrifugal effect due to Earth rotation.

[16] The horizontal components of the gravitational field describe in approximation the north-south and east-west inclination of the quasi/geoid with respect to the reference ellipsoid. The variation range of the horizontal field components (also known as deflections of the vertical) is about $\sim 200$ arc sec in north-south and $\sim 160$ arc sec in east-west, respectively (Table 1). GGMplus reveals a candidate location for Earth's largest deflection of the vertical: about $10 \mathrm{~km}$ south of Annapurna II, Nepal, the plumb line is expected to deviate from the ellipsoid normal by an angle as large as $\sim 109$ arc sec (Figure $3 \mathrm{c}$ and $3 \mathrm{~d}$ ). This translates into a most extreme quasi/ geoid slope of about $0.5 \mathrm{~m}$ over $1 \mathrm{~km}$.

\section{Model Evaluation}

[17] We have comprehensively compared GGMplus gravity field maps with in situ (direct) observations of Earth's gravity field from gravimetry, astronomy, and surveying (see supporting information). Over well-surveyed areas of North America, Europe, and Australia, the comparisons suggest an accuracy level for free-air gravity and gravity accelerations of $\sim 5 \times 10^{-5} \mathrm{~m} \mathrm{~s}^{-2}$, for horizontal field components of about 1 arc sec, and for quasi-geoid heights of $0.1 \mathrm{~m}$ or better.

[18] Despite the improvements conferred by recent satellite gravity to our model, the GGMplus accuracy deteriorates by a factor of $\sim 3$ to $\sim 5$ over Asia, Africa, and South America, which are regions with limited or very limited ground gravity data availability. Comparisons suggest a decrease in accuracy down to $\sim 20 \times 10^{-5} \mathrm{~m} \mathrm{~s}^{-2}$ for gravity, $\sim 5$ arc sec for horizontal field components, and $\sim 0.3 \mathrm{~m}$ for quasi-geoid heights. The reduced accuracy estimates mainly reflect the limited availability of gravity observations at spatial scales of $\sim 100$ to $\sim 10 \mathrm{~km}$. The accuracy of GGMplus gravity accelerations will always be lower than that of free-air gravity. This is because accelerations are directly affected by errors in the elevation data, with an elevation error of $10 \mathrm{~m}$ equivalent to about $3 \times 10^{-5} \mathrm{~m} \mathrm{~s}^{-2}$.

[19] Given that any gravity field signals originating from local mass-density variations are not represented by the topographic gravity, our gravity maps cannot provide information on geological units at scales less than $10 \mathrm{~km}$. This is akin to EGM2008 at spatial scales of $\sim 30$ to $\sim 10 \mathrm{~km}$ over many land areas where gravity measurements are unavailable or of proprietary nature [Pavlis et al., 2012]. Any global, regional, or local gravity map or quasi/geoid model can only be geologically interpreted down to a resolution commensurate with the gravity observations used to construct the model. Nevertheless, incorporation of topographic gravity to approximate gravity field features at spatial scales of $\sim 10 \mathrm{~km}$ to $\sim 250 \mathrm{~m}$ significantly improves GGMplus gravity and horizontal components when compared to $10 \mathrm{~km}$ resolution maps. Depending on the terrain ruggedness, the observed improvement rates mostly range between 40 and $90 \%$ for radial and horizontal field components (Tables S6 and S8), while the quasi-geoid improvement is best observable over rugged areas (up to $40 \%$ improvement, Table S9).

\section{Applications}

[20] Apart from enhancing our knowledge of Earth's gravity and its variations, there are several scientific and engineering applications that require high-resolution and largely complete gravity knowledge, which is now available through GGMplus gravity maps.

[21] The quasi/geoid plays a crucial role in modern determination of topographic heights with Global Navigation Satellite Systems (such as the Global Positioning System), allowing the measurement of heights above mean sea level rather than heights above the ellipsoid [e.g., Meyer et al., 2006; Featherstone, 2008; Hirt et al., 2011]. While several regional-size quasi/geoid models of good quality are available at mostly $\sim 2 \mathrm{~km}$ resolution over well-surveyed land areas (e.g., Europe, U.S., Australia), GGMplus is capable of providing improved quasi/geoid information over those parts of Asia, Africa, and South America, where no other source of high-resolution gravity (e.g., from airborne gravity) is available. The GGMplus quasi-geoid can be suitable for water flow modeling (e.g., as required in hydroengineering), and height transfer with satellite systems, and can be of utility for the determination of offsets among continental height 
systems (e.g., Australia and Europe) and their unification [e.g., Flury and Rummel, 2005; Rummel, 2012]. This in turn will allow for a more consistent comparison of sea level observations at tide gauges across the oceans. Because of incorporation of newer GOCE and GRACE satellite gravity, the GGMplus quasi-geoid confers improvements at $\sim 100$ $\mathrm{km}$ spatial scales over parts of Asia, South America, and Africa, while consideration of short-scale quasi-geoid effects from topography data improves the resolution of quasi-geoid heights over rugged terrain [Hirt et al., 2010].

[22] GGMplus gravity accelerations and free-air gravity are a promising data source for screening and outlier-detection of terrestrial gravity databases and aid in planning of local precision gravimetric surveys. Gravity accelerations as provided by our maps are required, e.g., as a correction in the context of geodetic height systems [e.g., Meyer et al., 2006], for accurate topographic mapping, in metrology for calibration of precision scales [Torge, 1989] and seismometers, and in observational astronomy for meteorological corrections (T. Corbard et al., On the importance of astronomical refraction for modern Solar astrometric measurements, submitted to Astronomy and Astrophysics, 2013). For geophysics and the exploration industry, GGMplus may prove beneficial as novel data source for in situ reduction of detailed gravimetric surveys, revealing locations of interest for mineral prospectivity without the need to calculate and apply further and rather timeconsuming reductions [Jacoby and Smilde, 2009]. Finally, horizontal field components are required to correct the impact of the Earth's irregular gravity field, e.g., for inertial navigation at or near the Earth's surface [Grejner-Brzezinska and Wang, 1998], or in the context of civil engineering (e.g., precision surveys for tunnel alignment) [Featherstone and Rüeger, 2000]. All of these applications require spectrally most complete information on the gravity field.

\section{Conclusions}

[23] GGMplus provides the most complete description of Earth's gravity at ultrahigh resolution and near-global coverage to date. This confers immediate benefits to many applications in engineering, exploration, astronomy, surveying, and potential field geophysics. While GGMplus provides moderate additional information (because of the ultrahigh-resolution short-scale modeling) over areas with dense coverage of gravity stations (e.g., North America, Europe, Australia), significant improvements are provided over areas with sparse ground gravity coverage (e.g., Asia, Africa, South America). For the latter regions, GGMplus provides for the first time a complete coverage with gravity at ultrahigh spatial resolution, thus providing scientific aid to many developing countries. In addition, GGMplus provides crucial information to revise current standards for the maximum range of free-fall gravity accelerations over the Earth's surface. The computerized GGMplus gravity field maps are freely available for science, education, and industry via and http://ddfe.curtin.edu.au/gravitymodels/GGMplus.

[24] Acknowledgments. We are grateful to the Australian Research Council for funding (DP120102441). This work was made feasible through using advanced computational resources of the iVEC/Epic supercomputing facility (Perth, Western Australia). We thank all developers and providers of data used in this study. Full methods and detailed evaluation results are available in the supporting information, and information on data access via the project's website http://geodesy.curtin.edu.au/research/models/GGMplus.
[25] The Editor thanks two anonymous reviewers for their assistance in evaluating this paper.

\section{References}

Balmino, G., N. Vales, S. Bonvalot, and A. Briais (2012), Spherical harmonic modelling to ultra-high degree of Bouguer and isostatic anomalies, J. Geod., 86(7), 499-520, doi:10.1007/s00190-011-0533-4.

Becker, J. J., et al. (2009), Global bathymetry and elevation data at 30 arc seconds resolution: SRTM30 PLUS, Mar. Geod., 32(4), 355-371.

Drinkwater, M. R., R. Floberghagen, R. Haagmans, D. Muzi, and A. Popescu (2003), GOCE: ESA's first Earth Explorer Core mission, in Earth Gravity Field From Space-From Sensors to Earth Sciences, Space Sciences Series of ISSI, vol. 18, edited by G. B. Beutler, M. R. Drinkwater, R. Rummel, and R. von Steiger, pp. 419-432, Kluwer Academic Publishers, Dordrecht, Netherlands.

Featherstone, W. E. (2008), GNSS-based heighting in Australia: Current, emerging and future issues, J. Spat. Sci., 53, 115-133.

Featherstone, W. E., and J. M. Rüeger (2000), The importance of using deviations of the vertical for the reduction of survey data to a geocentric datum, Aust. Surv., 45, 46-61.

Flury, J., and R. Rummel (2005), Future satellite gravimetry for geodesy, Earth Moon Planets, 94, 13-29, doi:10.1007/s11038-005-3756-7.

Forsberg, R. (1984), A Study of Terrain Reductions, Density Anomalies and Geophysical Inversion Methods in Gravity Field Modelling, Report 355, Department of Geodetic Science and Surveying, Ohio State University, Columbus.

Forsberg, R., and C. C. Tscherning (1981), The use of height data in gravity field approximation by collocation, J. Geophys. Res., 86(B9), 7843-7854.

Grejner-Brzezinska, D. A., and J. Wang (1998), Gravity modeling for highaccuracy GPS/INS integration, Navigation, 45(3), 209-220.

Hirt, C. (2010), Prediction of vertical deflections from high-degree spherical harmonic synthesis and residual terrain model data, J. Geod., 84(3), 179-190, doi:10.1007/s00190-009-0354-x.

Hirt, C. (2012), Efficient and accurate high-degree spherical harmonic synthesis of gravity field functionals at the Earth's surface using the gradient approach, J. Geod., 86(9), 729-744, doi:10.1007/s00190-012-0550-y.

Hirt, C. (2013), RTM gravity forward-modeling using topography/bathymetry data to improve high-degree global geopotential models in the coastal zone, Mar. Geod., 36(2), 183-202, doi:10.1080/01490419.2013.779334.

Hirt, C., W. E. Featherstone, and U. Marti (2010), Combining EGM2008 and SRTM/DTM2006.0 residual terrain model data to improve quasi-geoid computations in mountainous areas devoid of gravity data, J. Geod., 84(9), 557-567, doi:10.1007/s00190-010-0395-1.

Hirt, C., M. Schmitz, U. Feldmann-Westendorff, G. Wübbena, C.-H. Jahn, and G. Seeber (2011), Mutual validation of GNSS height measurements and high-precision geometric-astronomical levelling, GPS Solutions, 15(2), 149-159, doi:10.1007/s10291-010-0179-3.

Jacoby, W., and P. L. Smilde (2009), Gravity Interpretation, Springer, Berlin, Heidelberg.

Jarvis, A., H. I. Reuter, A. Nelson, and E. Guevara (2008), Hole-filled SRTM for the globe Version 4. [Available from the CGIAR-SXI SRTM 90m database, http://srtm.csi.cgiar.org.]

Kuhn, M., W. E. Featherstone, and J. F. Kirby (2009), Complete spherical Bouguer gravity anomalies over Australia, Aust. J. Earth Sci., 56, 213-223.

Mayer-Gürr, T., E. Kurtenbach, and A. Eicker (2010), ITG-Grace2010 Gravity Field Model. [Available at http://www.igg.uni-bonn.de/apmg/index.php?id=itg-grace2010.]

Meyer, T. H., D. R. Roman, and D. B. Zilkoski (2006), What does height really mean? Part IV: GPS heighting, Surveying Land Inf. Sci., 66, 165-183.

Mohr P. J., and B. N. Taylor (2005), CODATA recommended values of the fundamental physical constants: 2002, Rev. Mod. Phys., 77, 1-107.

Moritz, H. (2000), Geodetic Reference System 1980, J. Geod., 74, 128-140.

Pail, R., et al. (2010), Combined satellite gravity field model GOCO01S derived from GOCE and GRACE, Geophys. Res. Lett., 37, L20314, doi:10.1029/2010GL044906.

Pail, R., et al. (2011), First GOCE gravity field models derived by three different approaches, J. Geod., 85(11), 819-843, doi:10.1007/s00190-011-0467-x.

Pavlis, N. K., S. A. Holmes, S. C. Kenyon, and J. K. Factor (2012), The development and evaluation of the Earth Gravitational Model 2008 (EGM2008), J. Geophys. Res., 117, B04406, doi:10.1029/2011JB008916.

Rummel, R. (2012), Height unification using GOCE, J. Geod. Sci., 2, 355-362.

Sansò F., and M. G. Sideris (2013), The local modelling of the gravity field The terrain effects, in Lecture Notes in Earth System Sciences, vol. 110, p. 169, Springer, Berlin, Heidelberg.

Torge, W. (1989), Gravimetry, Walter de Gruyter, Berlin, New York.

Tziavos, I. N., and M. G. Sideris (2013), Topographic reductions in gravity and geoid modeling, in Lecture Notes in Earth System Sciences, vol. 110, pp. 337-400, Springer, Berlin Heidelberg. 